4. Молодая семья. [Электронный ресурс]. - URL: http://molodaja-semja.ru/programma-2021/. (Дата обращения: 23.07.2021 г.)

5. Новые виды господдержки в 2020 году. [Электронный pecypc]. - URL: https://www.gosuslugi.ru/help/news/2020_03_03_privileges. (Дата обращения: 23.07.2021 г.)

6. ВPM - системы. [Электронный ресурс]. - URL: https://bpm-systems.ru/bpm-system-about/. (Дата обращения: 24.07.2021 г.)

7. Итоги 2019-го и прогноз на 2020 год на рынке ипотеки: угроза заражения. [Электронный ресурс]. - URL: https://raexpert.ru/researches/banks/ipoteka_2019/\#part1. (Дата обращения: 24.07.2021 г.)

8. ВPM в банковском секторе. [Электронный ресурс]. - URL: https://www.comindware.com/ru/blogbpm-в-банковском-секторе/. (Дата обращения: 24.07.2021 г.)

9. Паспорт национального проекта «Жилье и городская среда». [Электронный pecypc]. - URL: http://static.government.ru/media/files/i3AT3wjDNyEgFywnDrcrnK7Az55RyRuk.pdf. $\quad$ (Дата обращения: 24.07.2021 г.)

\title{
Умнов В.А. \\ Анализ тенденций в сельскохозяйственной отрасли России и перспектив ее развития
}

Российский государственньй гуманитарный университет (Россия, Москва)

doi: $10.18411 / \mathrm{j}-08-2021-83$

\section{Аннотация}

Рассматриваются основные тенденции развития сельскохозяйственной отрасли России за период с 2005 по 2018 гг. на основе официальных данных Росстат. Проведен анализ изменения производства в отрасли в целом, в том числе с учетом ценовых факторов, а также отдельно по некоторым важным видам продукции. Исследованы тенденции изменения таких важных показателей, как доля добавленной стоимости в продукции, численности занятых и рентабельности отрасли.

Ключевые слова: сельское хозяйство, тенденции развития, производство, добавленная стоимость, численность работников, рентабельность.

\section{Abstract}

The main trends in the development of the agricultural industry in Russia for the period from 2005 to 2018 based on official data from Rosstat are considered. The analysis of changes in production in the industry, also taking into account price factors, as well as separately for some important types of products, is carried out. Trends in the change of such important indicators as the share of value added in production, the number of employees and the profitability of the industry have been investigated.

Keywords: agriculture, development trends, production, value added, number of employees, profitability.

Сельское хозяйство является одной из базовых для экономики страны отраслей. От эффективности производства аграрной продукции зависит не только уровень жизни населения, но и экономическая безопасность страны. С момента перехода к рыночной модели экономики данная отрасль претерпела существенные изменения. Важно проанализировать основные тенденции развития отрасли в целях дальнейшего формирования направлений государственного участия в отрасли и ее поддержки. В этой связи в работе был проведен анализ основных показателей отрасли по данным Росстат за период 2005-2018 гг. [1, 2, 3].

За период с 2005 по 2018 годы объем производства различных видов сельскохозяйственной продукции менялся по-разному, некоторые наименования в абсолютном значении выросли, другие - снизились. Производство скота и птицы выросло в 3 раза, производство зерна - в 1,5 раза, овощей - в 1,2 раза. Производство 
яиц выросло на $21 \%$, яиц - на 12\%. В то же время производство молока и молочных продуктов уменьшилось на $17 \%$, картофеля - на $20 \%$ (рис. 1).



Рис. 1. Изменение производства некоторых видов продукиии сельского хозяйства к 2005 году

Такие изменения производства свидетельствуют о трансформации структуры производства, вызванном потребительскими предпочтениями, а также влиянием импорта продовольственных товаров из других стран.

Валовая добавленная стоимость продукции сельского хозяйства имеет тенденцию к росту. Так с 2005 по 2018 гг. ее увеличение составило - 3,6 раза. Однако в период последнего кризиса с 2016 по 2018 г. можно заметить некоторое прекращение роста данного показателя (рис. 2).

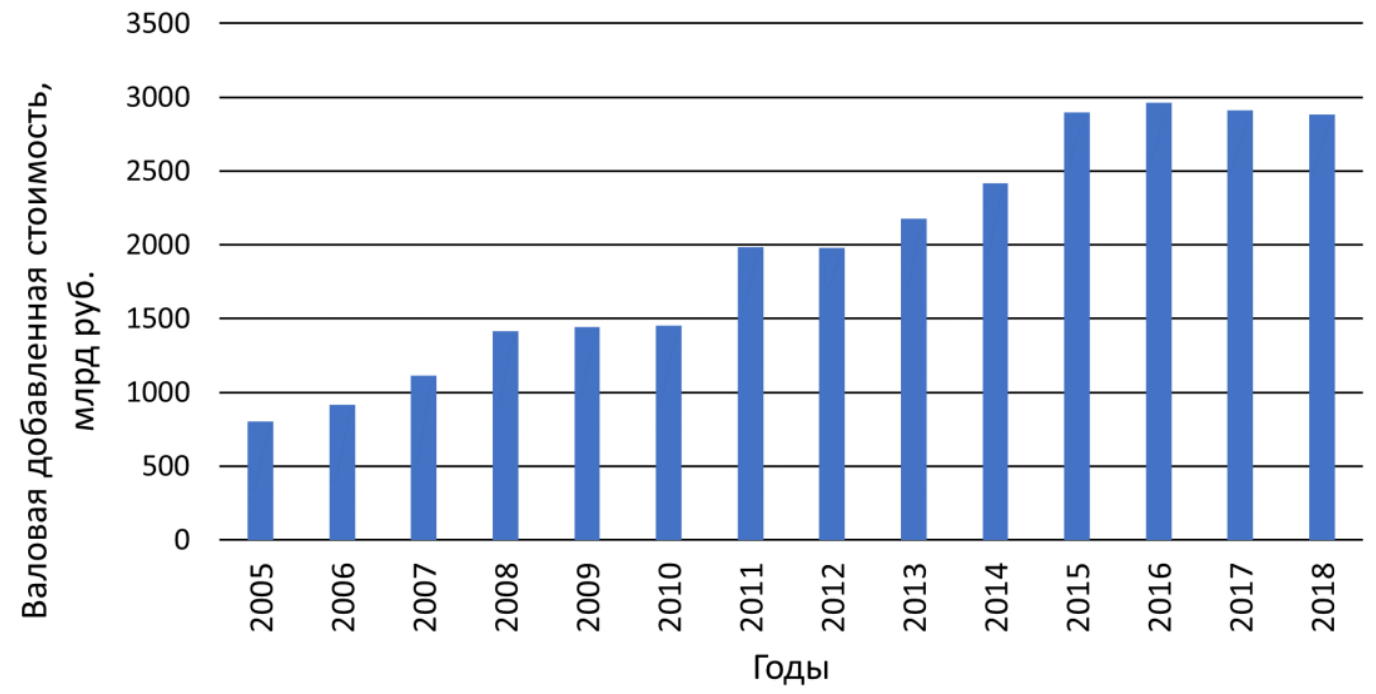

Рис. 2. Изменение валовой добавленной стоимости в сельском хозяйстве России

Поскольку для измерения роста сельскохозяйственной продукции используются стоимостные показатели, в целях большей точности анализа следует исключить влияние ценовых факторов. Поэтому произведен пересчет с учетом индекса цен (данные Росстат) к ценам 2005 года (рис. 3). 


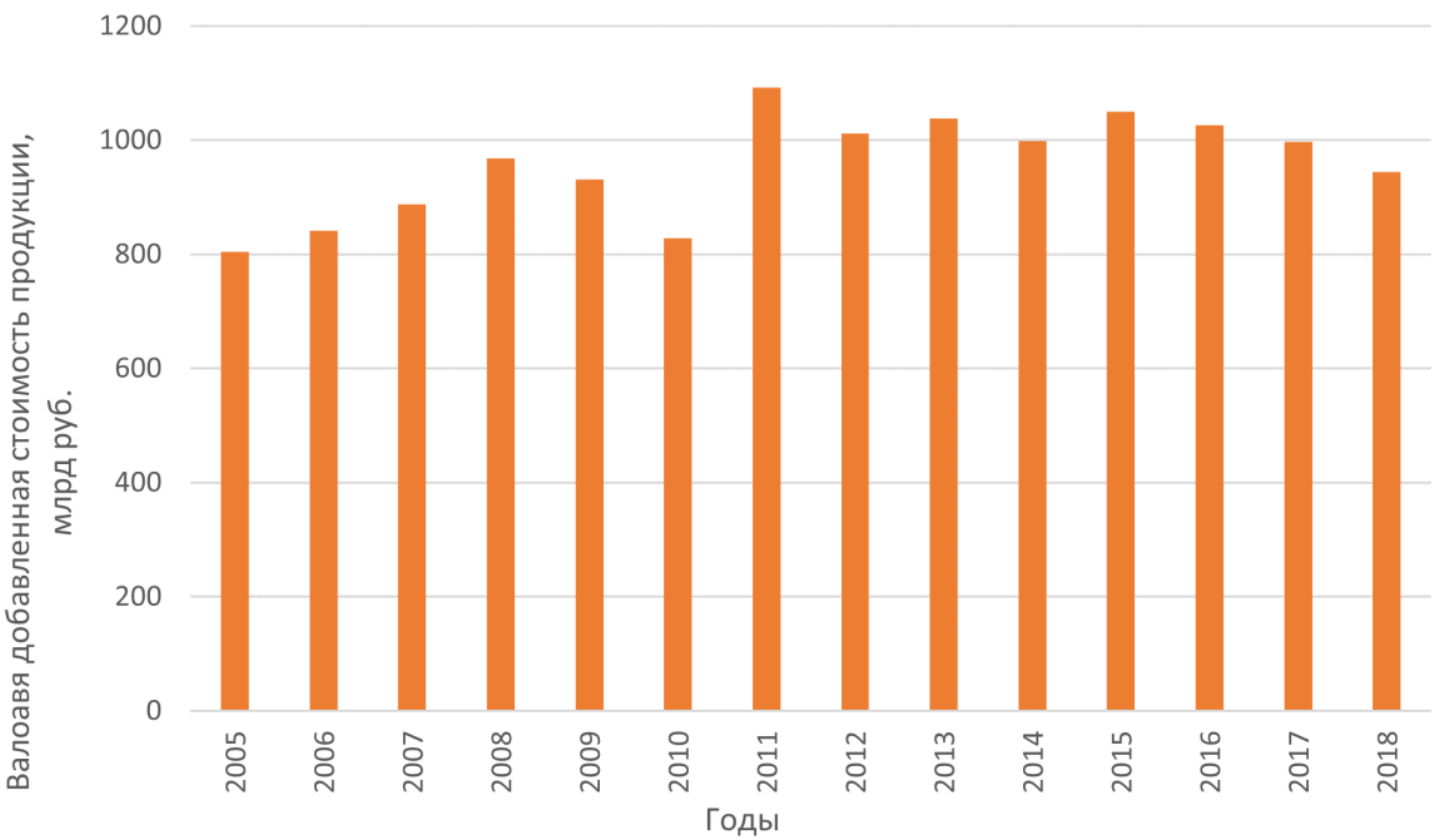

Рис. 3. Изменение валовой добавленной стоимости в сельском хозяйстве России с учетом индекса иен

Таким образом, с учетом индекса цен рост валовой добавленной стоимости в сельском хозяйстве России с 2005 по 2018 годы произошел лишь на $17 \%$. Максимальной величины данный показатель достигал в 2011 года. В 2010, 2012, 2014 и 2018 годах, в силу экономических кризисов, происходило заметное снижение валовой добавленной стоимости.

Если рассматривать долю добавленной стоимости в продукции сельского хозяйства Росси, то за анализируемый период она уменьшилась с 58,3\% до 53,8\% (рис 4.).



Рис. 4. Изменение доли добавленной стоимости в продукиии сельского хозяйства России

Снижение доли добавленной стоимости означает, что совокупные доходы инвесторов в сельское хозяйство, предпринимателей и заработная плата растут 
медленнее, чем объем производства. Это снижает мотивацию у предпринимателей и работников и как следствие - потенциал развития отрасли.

Если рассматривать с позиции роли сельского хозяйства среди других отраслей промышленности РФ, то удельный вес валовой добавленной стоимости сельского хозяйства в ВВП страны за анализируемый период снизился на 30 \%. Это позволяет сделать вывод о том, что сельское хозяйство развивается медленнее, чем экономика страны в целом (рис. 5).

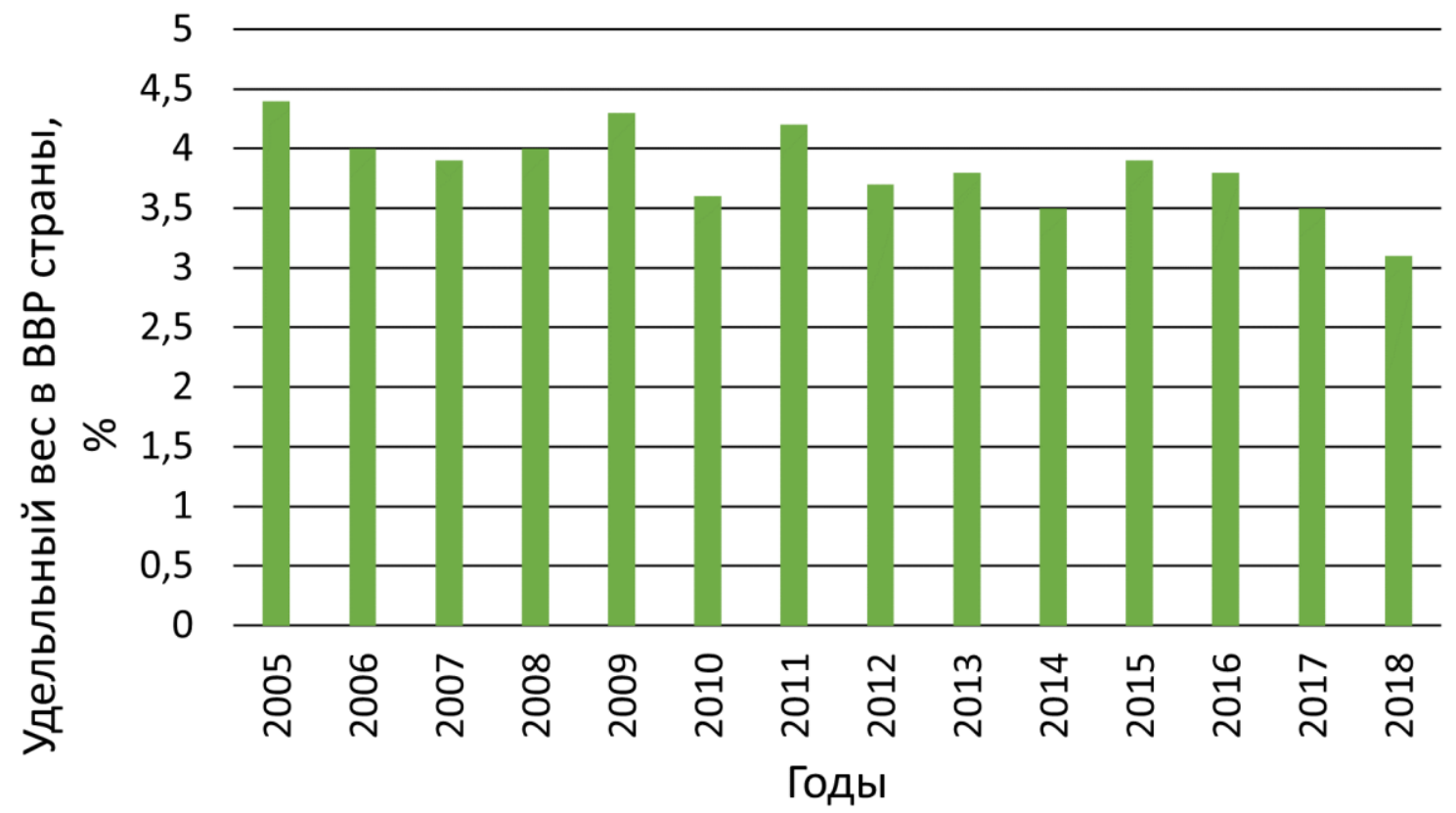

Рис. 5. Изменение удельного веса добавленной стоимости сельского хозяйства в ВВП страньл

Численность занятых по виду экономической деятельности «Растениеводство и животноводство, охота и предоставление соответствующих услуг в этих областях» с 2005 по 2018 годы существенно снизилась (рис. 6).

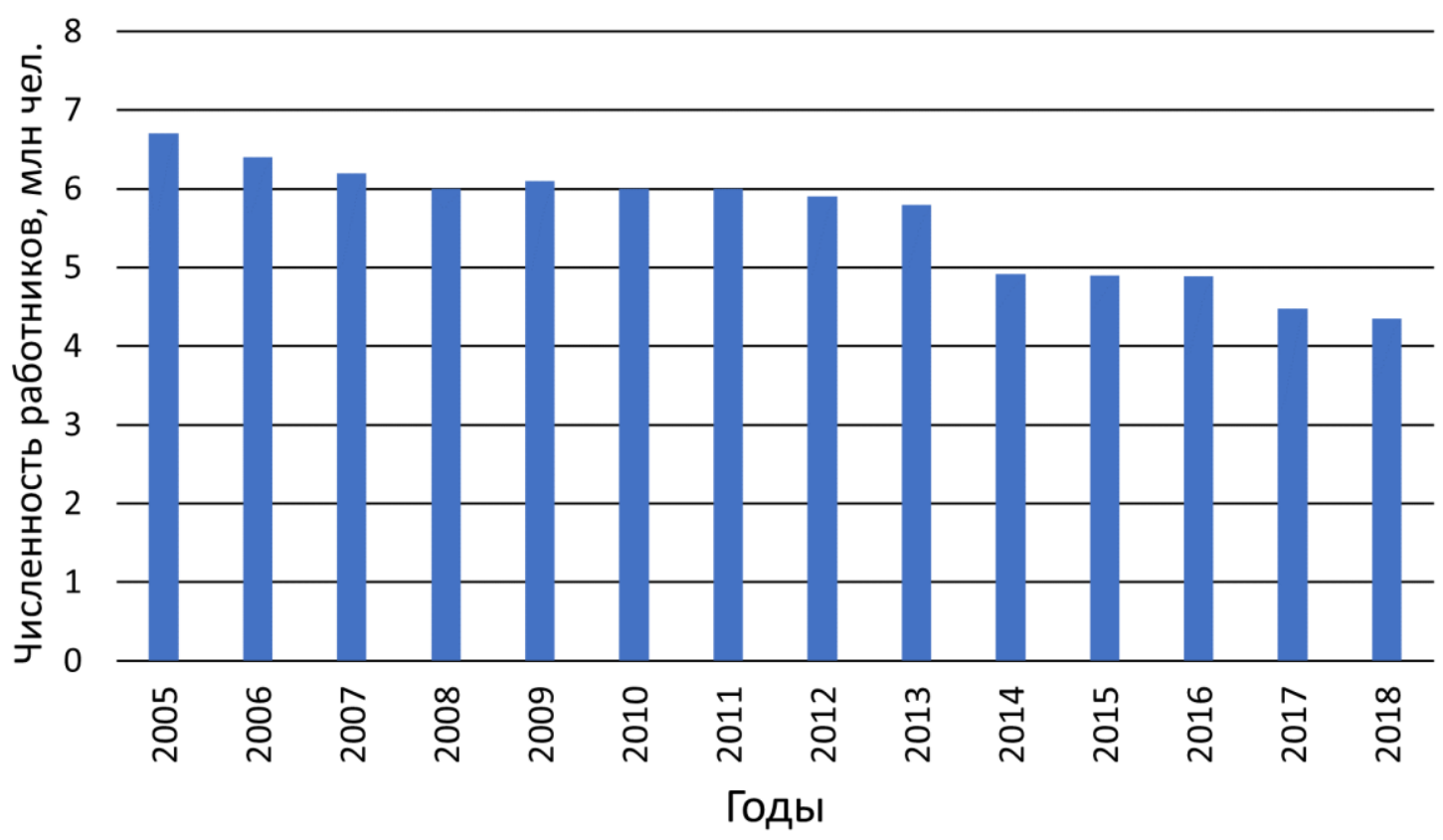

Рис. 6. Изменение численности занятых в сельском хозяйстве России 
Однако с учетом роста производства в целом можно сделать вывод о повышении производительности труда за счет применения более современных технологий и техники. На это может также влиять то, что далеко не все сельскохозяйственные рабочие являются официально трудоустроенными попадают в статистическую отчетность. Сезонность деятельности не стимулирует предпринимателей брать работников в штат. Система налогообложения крестьянских фермерских хозяйств не требует отчетности по затратам, включая затраты на заработную плату работникам. Рабочие-мигранты также зачастую нанимаются без официального оформления.

В то же время, если анализировать уровень рентабельности производства, в сельском хозяйстве он существенно вырос за рассматриваемый период и превысил рентабельность экономики страны в целом. На фоне сокращения количества работников и предприятий это может означать, что менее рентабельные хозяйства сокращаются, уступая место более эффективным (рис. 7).

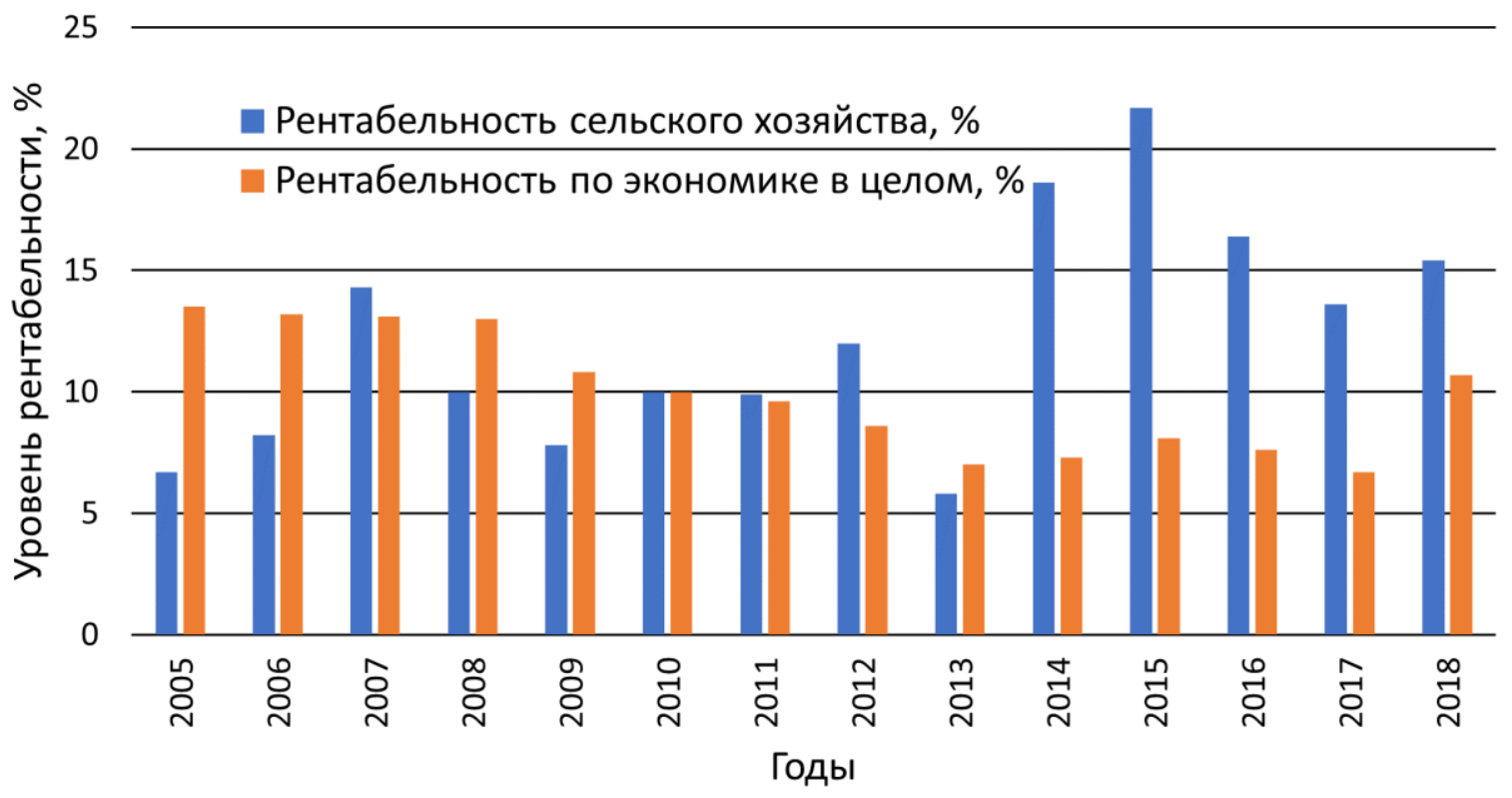

Рис. 7. Изменение уровня рентабельности сельского хозяйства и экономики странь в целом

В результате проведенного анализа можно сделать выводы о том, что с учетом ценовых факторов рост производства сельскохозяйственной продукции за последние десятилетия не столь существенен, как изменение структуры производства под влиянием потребностей рынка и импорта продукции из других стран. Доля добавленной стоимости в продукции и ее уровень относительно других отраслей снижаются. В основном это связано с повышением материальных затрат на сельскохозяйственное производство под влиянием ценовых факторов в экономике. Данный фактор отрицательно влияет на мотивацию предпринимателей, инвесторов и работников. Тем не менее, уровень рентабельности производства в отрасли растет за счет внедрения новых технологи и техники мелкими предпринимателями.

$$
* * *
$$

1. Сельское хозяйство в России: офиц. сайт. URL: https://rosstat.gov.ru/folder/210/document/13226 (дата обращения: 15.07.2021)

2. Российский статистический ежегодник: офиц. сайт. URL: https://rosstat.gov.ru/folder/210/document/12994 (дата обращения: 15.07.2021)

3. Всероссийская сельскохозяйственная перепись 2016 года: офиц. сайт. URL: URL: https://rosstat.gov.ru/519 (дата обращения: 15.07.2021) 